\title{
The association of HMGBI expression with clinicopathological significance and prognosis in Asian patients with colorectal carcinoma: a meta-analysis and literature review
}

\author{
This article was published in the following Dove Press journal: \\ OncoTargets and Therapy \\ 8 August 2016 \\ Number of times this article has been viewed
}

\section{Xiaoli Zhang ${ }^{1,2}$ \\ Jinming $Y^{1,2}$ \\ Minghuan $\mathrm{Li}^{2}$ \\ Hui Zhu \\ Xindong Sun ${ }^{2}$ \\ Li Kong ${ }^{2}$}

'Department of Oncology, Renmin Hospital of Wuhan University, Wuhan, Hubei Province, ${ }^{2}$ Department of Radiation Oncology, Shandong Cancer Hospital and Institute, Jinan, Shandong Province, People's Republic of China
Correspondence: Jinming Yu Department of Radiation Oncology, Shandong Cancer Hospital and Institute, 440 Jiyan Road, Jinan, Shandong Province, 250I I7, People's Republic of China

Tel +8653167626442

Fax +86 53I 6762 697।

Email sdyujinming@|26.com
Background: The association of high mobility group box 1 (HMGB1) expression with clinicopathological significance and prognosis in Asian patients with colorectal carcinoma (CRC) remains controversial. The purpose of this study was to conduct a meta-analysis and literature review to identify the role of HMGB1 in the development and prognosis of CRC in Asians.

Methods: All eligible studies regarding the association between HMGB1 expression in tissue with clinicopathological significance and prognosis in Asian patients with CRC published up to January 2015 were identified by searching PubMed, Web of Science, Chinese National Knowledge Infrastructure, and WanFang database. Analysis of pooled data was performed, while odds ratio (OR) or hazard radio with $95 \%$ confidence interval (CI) was calculated and summarized to evaluate the strength of this association in fixed- or random-effects model.

Results: The expression level of HMGB1 in CRC tissues was much higher than normal colorectal tissues $(\mathrm{OR}=27.35,95 \% \mathrm{CI} 9.32-80.26, P<0.0001)$ and para-tumor colorectal tissues (OR $=10.06,95 \%$ CI 4.61-21.95, $P<0.0001)$. There was no relation between the HMGB1 expression and sex, age, clinical $\mathrm{T}$ stage, tumor size, and location (colon or rectum cancer). However, a significant relation was detected between the HMGB1 expression and clinical stage (American Joint Committee on Cancer 7), lymph node metastasis, distant metastasis, tumor invasion depth, and differentiation rate $(P=0.002, P \leq 0.0001, P<0.0001, P<0.0001$, and $P=0.007$, respectively). Patients with higher HMGB1 expression had shorter overall survival time, whereas patients with lower level of HMGB1 had better survival (hazard ratio $=1.40$, 95\% CI 0.98-1.82, $P<0.0001)$.

Conclusion: In this meta-analysis, our results illustrated the significant relationship of HMGB1 protein overexpression in tissues with clinicopathological characteristics and prognosis of CRC. Thus, HMGB1 may be a promising marker in predicting the clinical outcome of patients with CRC. However, more well-designed studies of large sample size are warranted to validate the findings of current study.

Keywords: CRC, survival, correlation analysis, clinical study

\section{Introduction}

Colorectal carcinoma (CRC) is the third most frequently diagnosed carcinoma and cancer-related death globally. ${ }^{1}$ In the People's Republic of China, CRC ranks fifth in overall deaths as a result of cancers, and the incidence of CRC has been increasing all the time. ${ }^{2}$ Although in recent decades, mortality from CRC has dropped greatly, possibly due to new technologies available for earlier diagnosis and better treatment modalities 
such as molecular targeting agents against vascular endothelial growth factor and epidermal growth factor receptor, there are still an estimated 50,830 people dying of CRC annually. ${ }^{1}$ The invasive carcinoma development process from normal colon epithelium takes between 7 and 12 years. ${ }^{3}$ During this progression, many genetic and epigenetic factors may play an important role in a series of sequential and interrelated steps. ${ }^{4,5}$ There have been a lot of studies concerning the mechanism of the progression of CRC.

The high mobility group box 1 (HMGB1), which is generally known as a kind of nucleosomal nonhistone protein, is widely expressed and highly conserved in all metazoans and plants. A series of studies have reported that HMGB1 might be associated with almost every tumor type, particularly epithelial neoplasms. ${ }^{6-10}$ In addition, the association of HMGB1 overexpression and grim clinical outcome has been demonstrated in a variety of human malignancies, such as prostate, esophageal, pancreatic, hepatocellular, and nonsmall-cell lung cancers. ${ }^{11-15}$

Accumulating evidence indicated that HMGB1 was a crucial factor implicated in CRC growth, progression, angiogenesis, invasion, and metastasis. Although existing studies suggested that HMGB1 might be a potential biomarker to predict the prognosis of $\mathrm{CRC}$, some conflicting results have been reported. ${ }^{16-27}$ Whether the discrepancy in these data was the result of real heterogeneity or simply due to limited statistical power was still indistinct. In order to settle these controversial issues, we reviewed current knowledge with respect to the relationship between HMGB1 expression in tumor tissues and clinicopathological parameters, as well as survival of Asian patients with CRC and performed a metaanalysis to identify the role of HMGB1 during the development of CRC and as a potential diagnostic and therapeutic target in future treatment.

\section{Methods}

\section{Search strategy}

Relevant articles up to January 2015 were searched via the following electronic databases: Web of Science, PubMed, Chinese WanFang, and Chinese National Knowledge Infrastructure database. We searched for articles containing the following terms: high motility group box 1, HMGB1, or HMG-1, and colon cancer, rectal cancer, colorectal cancer, colon carcinoma, rectal carcinoma, colorectal carcinoma or CRC. The search results were confined to human populations, as well as to articles written in English or Chinese. If the same data or data subsets were found in more than one article, only the publication most recently reported or with the largest sample size was included.

\section{Selection criteria}

The inclusion criteria included: 1) the articles that evaluated the association between HMGB1 (protein/mRNA) expression and the clinicopathological significance of CRC patients; 2) patients included had to be of Asian origin; 3) the articles investigated the relationship between HMGB1 expression and the prognosis of patients with $\mathrm{CRC}$; 4) the studies had utilized immunohistochemistry to detect the expression level of HMGB1 in tumor tissues. The exclusion criteria included: 1) repetitive publications; 2) patients included were not of Asian origin; 3) articles that did not present the usable data in detail; 4) reviews, case reports, and case-only reports; 5) studies of cell culture models in vitro; 6) animal experiment studies.

\section{Data extraction and study assessment}

For each study, the following data: first author's name, country of origin, year of publication, sample size, clinicopathological characteristics of patients, and the expression of HMGB1 in tissues were extracted independently by two reviewers. The results were compared, and any discontent was discussed and eventually resolved by a consensus among all authors.

\section{Statistical analysis}

STATA statistical software (version 12.0, StataCorp LP, College Station, TX, USA) was used to conduct all data analyses. Heterogeneity between studies was assessed by $Q$-test and $I^{2}$ index. According to the heterogeneity results $\left(I^{2} \leq 50 \%\right.$, fixed effect model; $I^{2}>50 \%$, random-effect model), mean differences combined with $95 \%$ confidence intervals (CI) were calculated by using a fixed or random effect model. Meta-analysis was performed to compare HMGB1 expression in CRC with that in normal tissues and para-tumor tissues. The effect of HMGB1 on pathological factors and survival of CRC patients was considered as statistically significant if the corresponding 95\% CI for pooled hazard radio (HR)/odds ratio (OR) did not overlap 1. All $P$-values in this study were two-sided. Funnel plots were used to detect publication bias. The result stability was assessed through a sensitivity analysis by removing one study at a time.

\section{Results \\ Study characteristics}

A total of 321 articles were screened by titles and abstracts. According to the inclusion criteria, 20 articles with full text were selected for further examination. Four articles were excluded due to not presenting usable data; one with mean HMGB1 concentration in CRC tissues, ${ }^{28}$ one with 


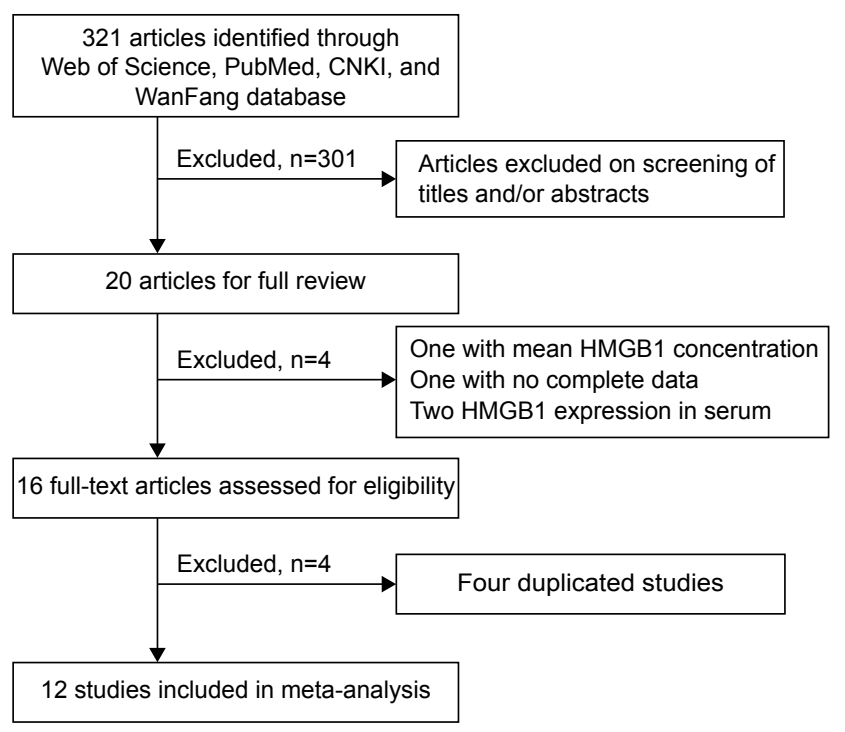

Figure I Flow chart for selection of included studies.

Note: Reasons for exclusion and number of studies excluded are shown.

Abbreviations: CNKI, Chinese National Knowledge Infrastructure; HMGBI, high mobility group box 1

no complete data, ${ }^{29}$ and two with only HMGB1 protein expression in serum. ${ }^{30,31}$ Furthermore, four articles were removed due to duplication. ${ }^{32-35}$ Twelve articles were chosen for full review in detail and meta-analysis. ${ }^{16-27}$ The following items were extracted from each study: first author's name, publication year, number of patients, tumor stage, detecting methods, HMGB1 expression level and patient prognosis. The flow chart of study selection is shown in Figure 1.
The total of 12 studies with 1,123 cases is summarized in Table 1.

\section{Quantitative data synthesis} HMGBI expression in CRC tissues and normal/paratumor colorectal tissues

HMGB1 protein expression in CRC tissues was much higher than normal tissues. ${ }^{21-22}$ The pooled OR for HMGB1 expression of CRC tissues versus normal colorectal tissues was 27.35 (95\% CI 9.32-80.26, $P<0.0001$, heterogeneity $I^{2}=0.76 \%$, Figure $2 \mathrm{~A}$ ). The pooled OR for HMGB1 expression in CRC tissues versus para-tumor colorectal tissues was 10.06 (95\% CI 4.61-21.95, $P<0.0001$, heterogeneity $r^{2}=63 \%$, Figure $\left.2 \mathrm{~B}\right)$.

\section{Relationship between clinicopathological features and HMGBI expression in CRC}

Meta-analysis of all studies assessing the relationship between clinicopathological features and HMGB1 expression are summarized in Table 2.

HMGBI overexpression and clinical stage of human CRC There were seven studies reporting the HMGB1 expression in patients with different clinical stages, ${ }^{16,17,19,21,23,26,27}$ of which four studies ${ }^{16,17,19,23}$ used Dukes classification for histopathological staging, ${ }^{36}$ one study ${ }^{26,27}$ used American Joint Committee on Cancer (AJCC) $7,{ }^{37}$ and one ${ }^{21}$ used AJCC 6 cancer staging. ${ }^{38}$ In order to conduct a meta-analysis of relationship between

Table I Main characteristics of included studies

\begin{tabular}{|c|c|c|c|c|c|}
\hline Study & Year & Country & $\begin{array}{l}\text { Sample } \\
\text { size }\end{array}$ & $\begin{array}{l}\text { Cancer } \\
\text { type }\end{array}$ & Comments \\
\hline Kuniyasu et $\mathrm{al}^{16}$ & 2003 & Japan & 119 & Colorectal & $\begin{array}{l}\text { Coexpression of RAGE and amphoterin is closely associated with } \\
\text { invasion and metastasis of colorectal cancer }\end{array}$ \\
\hline Kuniyasu et $\mathrm{al}^{17}$ & 2004 & Japan & 42 & Colon & $\begin{array}{l}\text { HMGBI expression is associated with clinical stage of colon cancer } \\
\text { patients }\end{array}$ \\
\hline Li et al $^{18}$ & 2006 & People's Republic of China & 70 & Colon & $\begin{array}{l}\text { HMGBI is associated with clinicopathological features in patients } \\
\text { with colon cancer }\end{array}$ \\
\hline Yao et al $^{19}$ & 2010 & People's Republic of China & 192 & Colorectal & High expression of HMGBI predicts poor prognosis for $\mathrm{CRC}$ \\
\hline Peng et $\mathrm{al}^{20}$ & 2010 & People's Republic of China & 72 & Colon & $\begin{array}{l}\text { The distribution patterns of HMGBI might contribute to the } \\
\text { progression of colon cancer }\end{array}$ \\
\hline Shi et $\mathrm{al}^{21}$ & 2012 & People's Republic of China & 70 & Colorectal & Detection and clinical significance of HMGBI in CRC patients \\
\hline Sun et $\mathrm{al}^{22}$ & 2012 & People's Republic of China & 127 & Rectal & $\begin{array}{l}\text { HMGBI is associated with clinicopathological features in patients } \\
\text { with rectal cancer }\end{array}$ \\
\hline Liu et $\mathrm{al}^{23}$ & 2013 & People's Republic of China & 66 & Rectal & Prognostic research of HMGBI protein expression in rectal cancer \\
\hline Zhu et $\mathrm{al}^{24}$ & 2015 & People's Republic of China & 40 & Colorectal & HMGBI mediates processes of tumor metastasis \\
\hline Ueda et $\mathrm{al}^{25}$ & 2014 & Japan & 140 & Colorectal & $\begin{array}{l}\text { HMGBI expression may be a predictor of postoperative lymph } \\
\text { node metastasis and prognosis in CRC }\end{array}$ \\
\hline Süren et $\mathrm{al}^{26}$ & 2014 & Turkey & 110 & Colorectal & The role of high $\mathrm{HMGBI}$ in $\mathrm{CRC}$ \\
\hline Hongo et $\mathrm{al}^{27}$ & 2015 & Japan & 75 & Rectal & $\begin{array}{l}\text { HMGBI plays a role in the development of carcinogenesis and } \\
\text { chemoresistance }\end{array}$ \\
\hline
\end{tabular}

Abbreviations: CRC, colorectal carcinoma; HMGBI, high mobility group box I; RAGE, receptor for advanced glycation endproducts. 


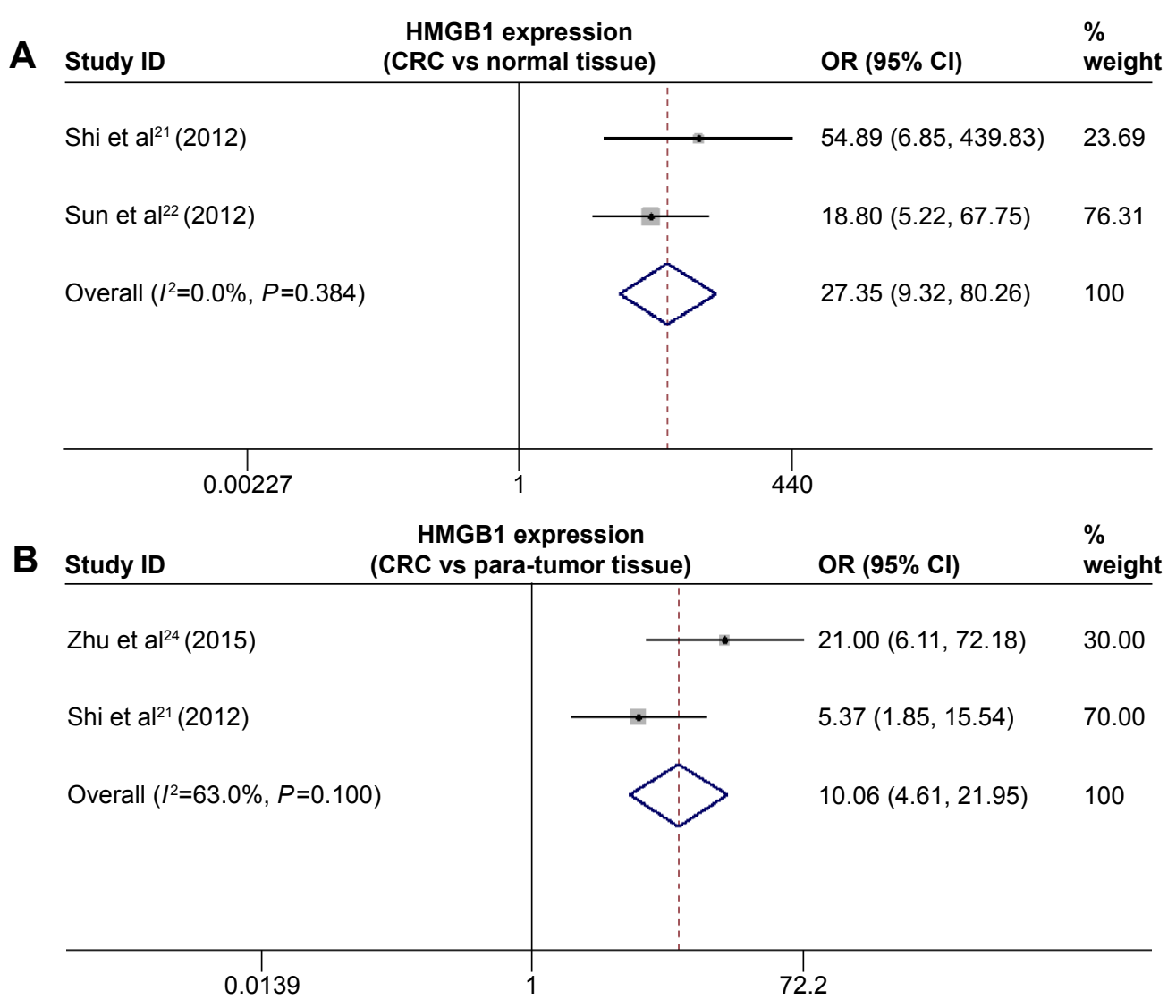

Figure 2 Forest plots of HMGBI expression in CRC and normal colorectal tissues/para-tumor tissues.

Notes: (A) HMGBI expression level in CRC tissues was significantly higher than normal colorectal tissues $(\mathrm{OR}=27.35,95 \% \mathrm{Cl} 9.32-80.26, \mathrm{P}<0.000 \mathrm{I})$. (B) $\mathrm{HMGBI}$ expression level in $C R C$ tissues was significantly higher than para-tumor tissues $(O R=10.06,95 \% \mathrm{Cl} 4.6 \mathrm{I}-2 \mathrm{I} .95, P<0.000 \mathrm{I})$.

Abbreviations: $\mathrm{Cl}$, confidence interval; $\mathrm{CRC}$, colorectal carcinoma; HMGBI, high mobility group box I; OR, odds ratio.

HMGB1 expression and clinical CRC stage, we made AJCC 7 cancer staging a standard for histopathological staging, and all patients in these seven studies were staged according to AJCC 7. The statistical analysis revealed that the positive rate of HMGB1 expression tended to be significantly higher in CRC tissues with clinical III/IV stage than with I/II stage
(OR $=4.01,95 \%$ CI 1.69-9.50, $P=0.002$, heterogeneity, $I^{2}=63 \%$, Figure $3 \mathrm{~A}$ ). Although no significant relationship was found between the HMGB1 expression and clinical T stage of tumor, CRC tissues of T3-4 tended to have a higher HMGB1 expression compared with $\mathrm{T} 1-2(\mathrm{OR}=2.41,95 \% \mathrm{CI} 0.96-6.06$, $P=0.06$, heterogeneity, $P^{2}=4.40 \%$, Figure $\left.3 \mathrm{~B}\right)$.

Table 2 Summary of the meta-analysis data between the HMGBI and clinicopathological characteristics

\begin{tabular}{|c|c|c|c|c|c|}
\hline \multirow[t]{2}{*}{ Clinical factor } & \multirow{2}{*}{$\begin{array}{l}\text { Studies } \\
\text { included in the } \\
\text { analysis }(n)\end{array}$} & \multicolumn{2}{|l|}{ OR } & \multicolumn{2}{|c|}{ Heterogeneity } \\
\hline & & $\begin{array}{l}\text { Summary OR } \\
(95 \% \mathrm{Cl})\end{array}$ & $P$-value & $I^{2}$ score $(\%)$ & $P$-value \\
\hline Clinical stage (III/IV vs I/II) & 7 & $4.01(1.69-9.50)$ & 0.002 & 63.00 & 0.013 \\
\hline Clinical T stage (T3/T4 vs $T I / T 2)$ & 2 & $2.41(0.96-6.06)$ & 0.06 & 4.40 & 0.306 \\
\hline LNM (positive vs negative) & 8 & $3.03(1.79-5.13)$ & $<0.0001$ & 55.70 & 0.027 \\
\hline DM (positive vs negative) & 5 & $3.81(2.12-6.84)$ & $<0.0001$ & 4.00 & 0.384 \\
\hline Differentiation rate (moderate/bad vs good) & 9 & $2.13(1.23-3.70)$ & 0.007 & 57.80 & 0.015 \\
\hline Invasion of serosa (positive vs negative) & 4 & $3.43(2.17-5.44)$ & $<0.0001$ & 32.60 & 0.217 \\
\hline Tumor location (colon vs rectum) & 2 & $1.40(0.85-2.32)$ & 0.189 & 0.10 & 0.317 \\
\hline Sex (female vs male) & 7 & $1.16(0.83-1.62)$ & 0.392 & 0.00 & 0.731 \\
\hline Age ( $<60$ vs $>60$ years) & 5 & $0.80(0.52-1.23)$ & 0.303 & 27.90 & 0.236 \\
\hline Tumor size $(<5 \mathrm{vs}>5 \mathrm{~cm})$ & 2 & $0.75(0.45-1.28)$ & 0.293 & 0.00 & 0.667 \\
\hline
\end{tabular}

Abbreviations: $\mathrm{Cl}$, confidence interval; DM, distant metastases; HMGBI, high mobility group box I; LNM, lymph node metastases; OR, odds ratio. 
HMGBI overexpression and migration in human CRC

A significant relationship was also detected between the HMGB1 expression and lymph node status $(P<0.0001$, Figure 3C) as well as distant metastases (DM) status $(P<0.0001$, Figure 3D) at diagnosis. Meta-analysis of eight studies revealed that HMGB1 expression levels in patients with lymph node metastases (LNM) were much higher than those with no LNM (OR $=3.03$, 95\% CI 1.79-5.13, $P<0.0001$, heterogeneity, $P^{2}=55.70 \%$, Figure 3C)..$^{18,19,21-23,25-27}$ When the analysis was stratified by DM status, five studies summarized that the usable data and immunoreactivity were observed more frequently in patients with DM than in nonmetastatic cases $(\mathrm{OR}=3.81,95 \%$ CI 2.12-6.84, $P<0.0001$, heterogeneity, $I^{2}=4 \%$, Figure $\left.3 \mathrm{D}\right) .{ }^{16,19,21,25,26}$

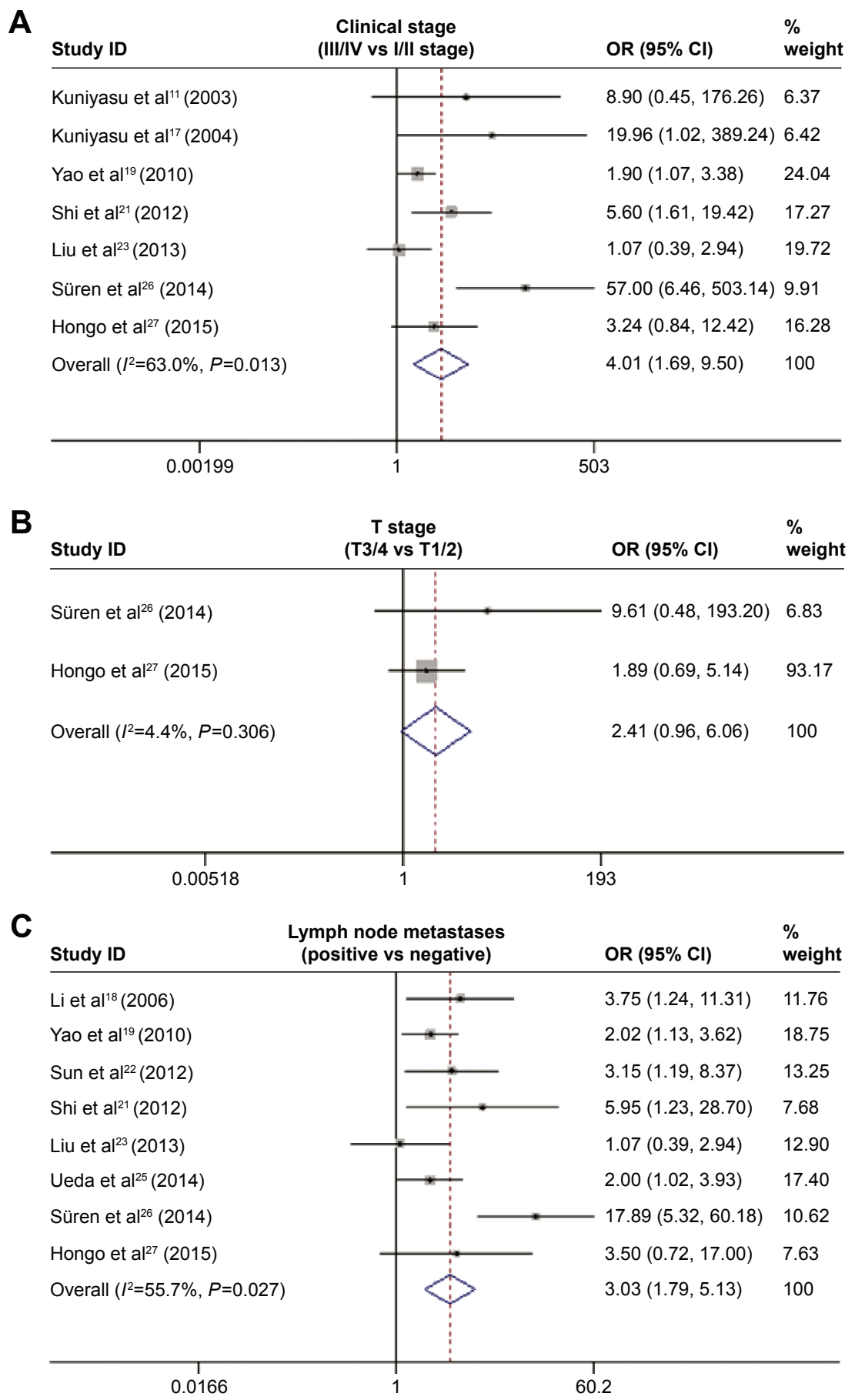

Figure 3 (Continued) 


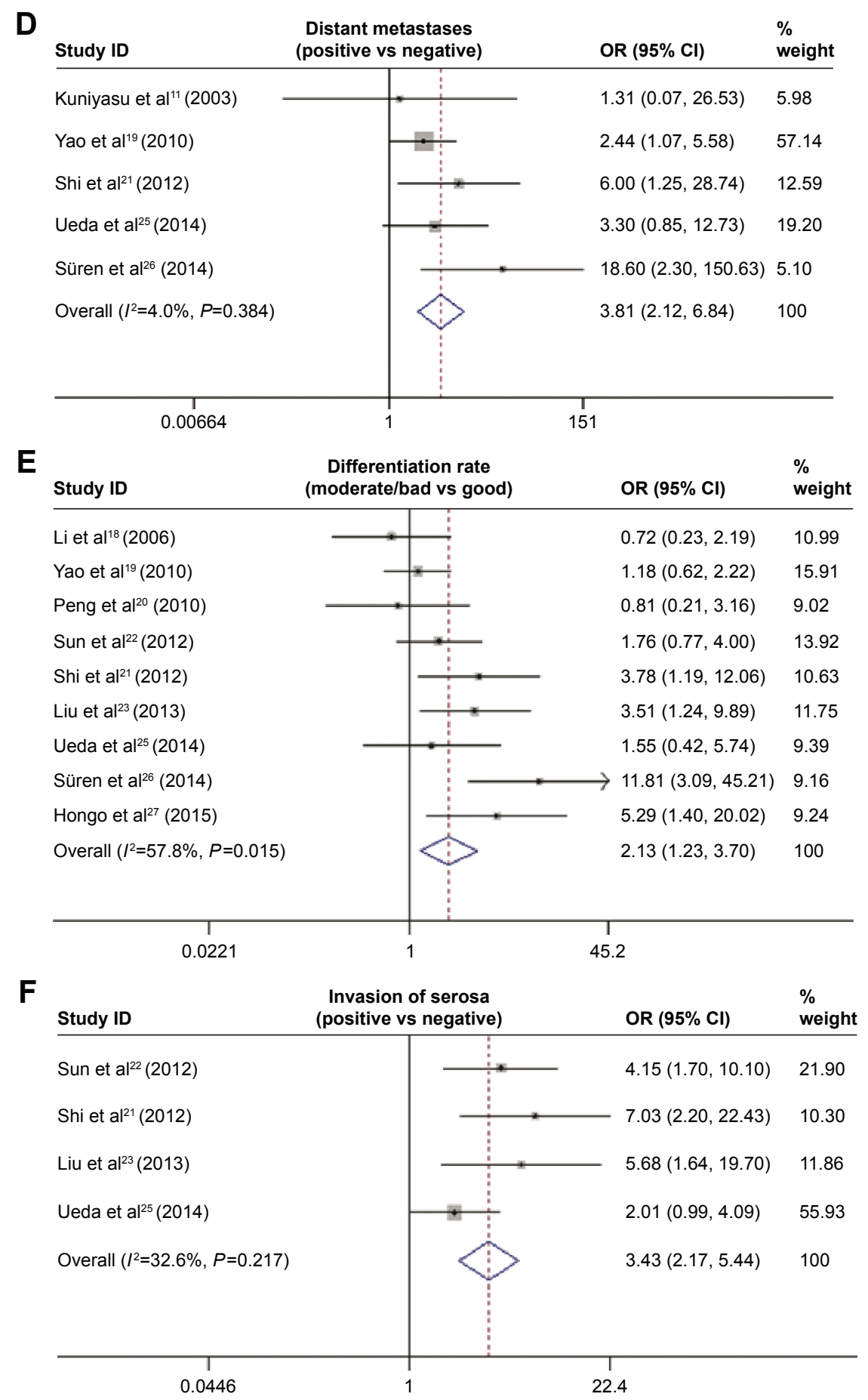

Figure 3 Forest plots of HMGBI expression and clinicopathological characteristics.

Notes: (A) The relationship between HMGBI expression and clinical stage of $C R C$ patients. $\mathrm{HMGBI}$ expression was related to clinical stage $(\mathrm{OR}=4.0 \mathrm{I}, 95 \% \mathrm{CI} I .69-9.50, \mathrm{P}=0.002)$. (B) The relationship between HMGBI expression and T stage of $C R C$ patients. HMGBI expression was not related to clinical stage (OR =2.4I, 95\% CI 0.96-6.06, $P=0.06$ ). (C) The relationship between $\mathrm{HMGBI}$ and status of lymph node. $\mathrm{HMGBI}$ expression was related to lymph node metastases $(\mathrm{OR}=3.03,95 \% \mathrm{CI}$ I.79-5. I3, $P<0.000 \mathrm{I})$. (D) The relationship between $\mathrm{HMGBI}$ and distant migration. HMGBI protein expression was related to distant migration $(\mathrm{OR}=3.8 \mathrm{I}, 95 \% \mathrm{Cl} 2.12-6.84, P \leq 0.000 \mathrm{I})$. (E) The relationship between $\mathrm{HMGBI}$ and tumor differentiation rate. $\mathrm{HMGBI}$ expression was related to tumor differentiation rate $(\mathrm{OR}=2.13,95 \% \mathrm{Cl}$ I.23-3.70, $P=0.007)$. (F) The relationship between $\mathrm{HMGBI}$ and tumor depth. HMGBI expression was related to tumor depth $(\mathrm{OR}=3.43,95 \% \mathrm{Cl} 2.17-5.44, P<0.000 \mathrm{I})$. Weights are from random effect analysis.

Abbreviations: $\mathrm{Cl}$, confidence interval; $\mathrm{CRC}$, colorectal carcinoma; HMGBI, high mobility group box I; OR, odds ratio.

\section{HMGBI overexpression and pathological characteristics} of human CRC

Stratification based on the tumor differentiation rate and invasion depth showed significant associations between
HMGB1 expression and the risk of poor differentiation $(P=0.007$, Figure 3E) and deep invasion cancer $(P<0.0001$, Figure 3F). Six studies compared the HMGB1 expression of moderate/poor and good differentiation tumor tissue. ${ }^{18-23,25-27}$ 


\begin{tabular}{|c|c|c|c|}
\hline Study ID & $\begin{array}{c}\text { Overall survival } \\
\text { (HMGB1 positive vs negative) }\end{array}$ & HR $(95 \% \mathrm{Cl})$ & $\begin{array}{l}\% \\
\text { weight }\end{array}$ \\
\hline Yao et al ${ }^{19}(2010)$ & & $1.56(1.02,2.40)$ & 36.86 \\
\hline Peng et al ${ }^{20}(2010)$ & & $1.11(0.61,1.99)$ & 37.24 \\
\hline Ueda et $\mathrm{a}^{25}(2014)$ & & $1.59(1.00,2.65)$ & 25.90 \\
\hline Overall $\left(I^{2}=0.0 \%, P=0.570\right)$ & & $1.40(0.98,1.82)$ & 100 \\
\hline
\end{tabular}

Figure 4 Forest plot of HMGBI expression and survival of CRC patients.

Notes: Patients with positive expression of HMGBI exhibited a shorter overall survival than those with negative expression (HR $=\mathrm{I} .40,95 \% \mathrm{CI} 0.98-\mathrm{I} .2, \mathrm{P}<0.000 \mathrm{I}$ ). Abbreviations: $\mathrm{Cl}$, confidence interval; CRC, colorectal carcinoma; HMGBI, high mobility group box I; HR, hazard ratio.

The meta-analysis result revealed that moderate/poor tumor tissues had a higher HMGB1 expression positive rate (OR $=2.13,95 \%$ CI 1.23-3.70, $P=0.007$, heterogeneity, $I^{2}=57.80 \%$, Figure $3 \mathrm{E}$ ). In the subgroup analysis on tumor invasion depth, the meta-analysis of four studies found that the HMGB1 expression level in CRC with direct extension through the serosa was significantly higher than those without (OR $=3.43,95 \%$ CI 2.17-5.44, $P<0.0001$, heterogeneity, $I^{2}=32.6 \%$, Figure $\left.3 \mathrm{~F}\right) .^{21-23,25}$ No difference was found in HMGB1 expression of CRC tissues between tumor size $<5$ and $\geq 5 \mathrm{~cm}(\mathrm{OR}=0.75,95 \% \mathrm{CI} 0.45-1.28, P=0.293$, heterogeneity, $\left.I^{2}=0.0 \%\right) \cdot{ }^{19,21}$

HMGBI overexpression and basic clinical characteristics of human CRC

In the subgroup analyses onsex, ${ }^{18-23,26,27}$ age, ${ }^{18,20-23}$ and tumor location (colon or rectal cancer), ${ }^{19,21}$ no differences were observed in the HMGB1 expression in females and males (OR $=1.16,95 \%$ CI 0.83-1.62, $P=0.392$, heterogeneity, $I^{2}=0 \%$ ), age $<60$ years and $\geq 60$ years $(\mathrm{OR}=0.80$, 95\% CI $0.52-1.23, P=0.303$, heterogeneity, $I^{2}=27.90 \%$ ), colon and rectal cancer $(\mathrm{OR}=1.40,95 \%$ CI $0.85-2.32$, $P=0.189$, heterogeneity, $I^{2}=10.0 \%$ ).

Relationship between survival and HMGBI expression in CRC

Furthermore, we found that patients with positive expression of HMGB1 exhibited a shorter overall survival than those with negative expression ( $\mathrm{HR}=1.40,95 \%$ CI $0.98-18.2$, $P<0.0001$, Figure 4). ${ }^{19,20,25}$

\section{Sensitivity analyses and publication bias}

The stability of these results was assessed by sensitivity analysis by excluding every study individually. The omission of any single study did not change the statistical significance. Funnel plot was carried out to evaluate the potential publication bias in the available literature and no evidence of obvious asymmetry existed.

\section{Discussion}

HMGB1 is a highly conserved nuclear protein, generally considered a chromatin-binding factor, which bends DNA and promotes access to transcriptional protein assemblies on specific DNA targets. ${ }^{39,40}$ Previous studies have revealed that HMGB1 is a dual-role protein. Apart from its nuclear role, HMGB1 can also act as an extracellular signaling molecule during a variety of activities, including inflammation, cell differentiation, migration, tumor metastasis, and so on. ${ }^{8,39-41}$ In this study, we performed a comprehensive literature search in different available databases and included additional studies, which allowed for a greater number of subjects (12 studies, including 1,123 cases in total) and more risk evaluation, to verify the role of HMGB1 in the growth, progression, invasion metastases, and survival of Asian patients with CRC. Previous studies conducted in non-Asian patients with CRC have also found a significant relationship between HMGB1 expression and CRC. But considering the lack of such experiments and relatively small sample size of the existing data, we only included studies about Asian patients with CRC.

Our data showed that the expression level of HMGB1 was significantly higher in CRC tissues compared with normal tissues, which suggested the possible important role played by HMGB1 in the development of CRC. The study conducted by Shi et al has found a significant difference in HMGB1 expression between $\mathrm{CRC}$ and normal tissues $(P<0.0001)$, $\mathrm{CRC}$ and para-tumor colorectal tissues $(P<0.0001)$, implying 
that HMGB1 expression levels in CRC were dramatically increased compared with those in normal tissues and para-tumor colorectal tissues, respectively. ${ }^{21}$ All of these results suggested that HMGB1 might be a key mediator during the development and progression of tumor.

Furthermore, the results of meta-analysis showed that the overexpression of HMGB1 in tissues was associated with clinical stage, depth of invasion, LNM, and DM in CRC patients. In the study conducted by Süren et al, a significant relationship was determined between HMGB1 and perineural invasion, lymphovascular invasion, and lymphocytic response ( $P<0.001, P<0.001$, and $P<0.001$, respectively) ${ }^{26}$ Kusume et al also reported that nodal metastasis-positive patients showed higher HMGB1 concentrations in both primary tumor and regional lymph node tissues than metastasis-negative cases. ${ }^{28}$ Studies in head-neck, hepatocellular carcinoma, ovarian and esophageal squamous cell cancer have demonstrated similar results. ${ }^{12,42-45}$ These findings support the hypothesis that HMGB1 has, at least, facilitating effects on LNM, DM, and increasing effects on the depth of tumor invasion in CRC. Nevertheless, HMGB1 expression levels were not associated with clinical $\mathrm{T}$ stage as well as tumor size in our study. For tumor development, tumor cells have to go through a multistep process (a series of sequential and selective events). Therefore, our results might be influenced by other cytokines or signaling molecules besides HMGB1 that contribute to tumor growth.

The clinicopathological factors, including sex, age, and tumor location, did not have close relationships with the expression of HMGB1, which was in accordance with studies of other solid tumors. ${ }^{7,12,42,43}$ Thus, it was plausible that HMGB1, isolated from effects of basic characteristics of patients, could serve as a promising biochemical marker of tumor. In addition, Lee et al have reported that, for stage I CRC patients, the diagnostic accuracy of HMGB1 in serum was dramatically higher than that of carcinoembryonic antigen in serum (sensitivity, $41.2 \%$ vs $5.9 \%$ and specificity, $96 \%$ vs $90.7 \%$ ), which was the most commonly used serum marker for early diagnosis of CRC. ${ }^{30,44}$ Progression of cancer is associated with enhanced deregulation of key signaling pathways, thus different stages of cancer might trigger different genes or proteins. ${ }^{46}$ The combination of several highly specific biomarkers may prove effective in making clinical decision, such as referral for colonoscopy or other noninvasive detections, or potentially may assist in diagnosing or treating recurrent disease. ${ }^{46}$

Three studies selected for this meta-analysis provided original survival data in detail, and the result of meta-analysis showed that HMGB1 overexpression might be closely linked to poorer clinical outcome of CRC patients. In the study conducted by Yao et al, the multivariate analysis indicated that HMGB1 overexpression might be an independent prognostic indicator for CRC patients. ${ }^{19}$ Another study, also conducted in Chinese patients with $\mathrm{CRC}$, reported that the 5-year survival rate of patients with positive HMGB1 expression was significantly worse than those with negative expression $(73.3 \%$ vs $82.1 \%, P=0.031) .{ }^{23}$ In addition, all the clinicopathological factors, including clinical stage, LNM, DM, moderate/poor tumor differentiation rate, and deep invasion, which had been verified by the meta-analysis to be associated with HMGB1 overexpression in tumor tissues, were all major prognostic factors in CRC. This indirectly verified the strong correlation between HMGB1 expression and the survival of CRC patients. ${ }^{47}$ Moreover, Peng et al demonstrated that the distribution patterns of HMGB1 might also contribute to the progression of colon cancer. ${ }^{20,32}$

HMGB1 as a multifunctional protein possesses diverse biological activities and the precise mechanism of HMGB-1 in cancer is still obscure. ${ }^{48}$ It is generally believed that diverse functions of HMGB1 are carried out in the nucleus, cytoplasm, and extracellular milieu. As a nuclear protein, HMGB1 takes part in multiple processes, including transcription, replication, recombination, and DNA repair. In cytoplasm, HMGB1 is associated with cell migration activity, antiapoptosis, autophagy, and so on. Most of the HMGB1, which is secreted into the extracellular milieu, plays a role in cancer progression through the receptor for advanced glycation endproducts (RAGE). ${ }^{36,49-52}$ HMGB1-RAGE signaling could result in nuclear translocation of NF- $\kappa \mathrm{B}$, neovascularization, tumorigenesis, and metastasis. In addition, HMGB1RAGE also takes part in the following activities: activation of endothelial cells, migration of smooth muscle cells, mesangioblast recruitment, migration, and proliferation. ${ }^{53}$ Moreover, HMGB1 plays a critical role in promoting the invasiveness of cancer cells through the activation of MMP pathway. ${ }^{22-24}$ Besides, HMGB1 could possibly activate other innate receptors, such as TLR4 and TLR2. ${ }^{8,54,55}$ These findings suggest an autocrine and/or paracrine role of HMGB1 in cancer progression. Furthermore, HMGB1 has been reported to play a key role in the immune system by dose-dependent effects on macrophages: a low level of HMGB1 activate macrophages to secrete inflammatory cytokines ${ }^{56,57}$ and a high level of HMGB1 induces apoptosis of macrophages, ${ }^{58}$ which implies that HMGB1 has obvious suppressive effects on anti-cancer immunity. Recent study conducted by Chiba et al has found that dendritic cell-derived TIM-3 interacted with HMGB1 to suppress the transport of nucleic acids into endosomal vesicles, thus attenuating the antitumor 
efficacy of DNA vaccines and cytotoxic chemotherapy by antagonizing nucleic acid-sensing systems. ${ }^{59}$ This added one more piece of evidence to support our claim that HMGB1 might have helped in the development of treatment resistance through its interaction with other cytokines, molecules that carry chemical signals between cells.

With the appearance of more and more evidence indicating that HMGB1 targeting is a possibly potential therapeutic technique against $\mathrm{CRC}$ development, progression, and, particularly, metastasis, many researchers have employed various methods to control the expression and secretion of HMGB1. With respect to the essential role of HMGB1 in cell activity and innate immunity, inhibition of HMGB1 might result in heavy side effects in human. All the experimental procedures have been limited to animal or cell line sample until now. ${ }^{60-62}$

\section{Limitations}

Some limitations should not be ignored in results of the current meta-analysis. First, the number of published studies and patients included was not large enough for a comprehensive analysis, especially for subgroup analysis according to different clinicopathological factors. Thus, we may mistake the real relationship between HMGB1 overexpression and CRC. In addition, most of the included studies were conducted in the People's Republic of China and the results in other Asian countries may be different. Second, due to the lack of access to original source data, all our analyses were based on singleparameter estimates without adjustment for different risk factors, which may have led to serious confounding bias. Third, the variable concentrations of antibodies and the inconsistent definitions of HMGB1 overexpression used in the included articles might have some effect on the results of our metaanalysis. Additional well-designed studies of large sample size are warranted to validate the findings of the current study.

\section{Conclusion}

HMGB1 expression level of CRC tissues is significantly higher than that of normal and para-tumor colorectal tissues. Overexpression of HMGB1 in tissues is significantly relevant in the prognosis of patients with CRC, and HMGB1 may be a potential diagnostic biomarker and therapeutic target for Asian patients suffering from CRC. However, further investigations with large sample size, multicenter, prospective, stratified, randomized clinical trials are needed to verify the current conclusion and clarify the underlying mechanism.

\section{Disclosure}

The authors report no conflicts of interest in this work.

\section{References}

1. Siegel R, Naishadham D, Jemal A. Cancer statistics, 2013. CA Cancer J Clin. 2013;63(1):11-30.

2. You WC, Jin F, Devesa S, et al. Rapid increase in colorectal cancer rates in urban Shanghai, 1972-1997, in relation to dietary changes. $J$ Cancer Epidemiol Prev. 2002;7(3):143-146.

3. Kim GP, Colangelo LH, Wieand HS, et al. Prognostic and predictive roles of high-degree microsatellite instability in colon cancer: a National Cancer Institute-National Surgical Adjuvant Breast and bowel project collaborative study. J Clin Oncol. 2007;25(7):767-772.

4. Han DP, Zhu QL, Cui JT, et al. Polo-like kinase 1 is overexpressed in colorectal cancer and participates in the migration and invasion of colorectal cancer cells. Med Sci Monit. 2012;18(6):BR237-BR246.

5. Gao L, Bai L, Nan Qz. Activation of Rho GTPase Cdc42 promotes adhesion and invasion in colorectal cancer cells. Med Sci Monit Basic Res. 2013;19:201-207.

6. Campana L, Bosurgi L, Rovere-Querini P. HMGB1: a two-headed signal regulating tumor progression and immunity. Curr Opin Immunol. 2008;20(5):518-523.

7. Chen J, Xi B, Zhao Y, Yu Y, Zhang J, Wang C. High-mobility group protein B1(HMGB1) is a novel biomarker for human ovarian cancer. Gynecol Oncol. 2012;126(1):109-117.

8. Ellerman JE, Brown CK, de Vera M, et al. Masquerader: high mobility group box-1 and cancer. Clin Cancer Res. 2007;13(10): 2836-2848.

9. Kang R, Zhang Q, Zeh HJ 3rd, Lotze MT, Tang D. HMGB1 in cancer: good, bad, or both? Clin Cancer Res. 2013;19(15):4046-4057.

10. Tang D, Kang R, Zeh HJ 3rd, Lotze MT. High-mobility group box 1 and cancer. Biochim Biophys Acta. 2010;1799(1-2):131-140.

11. Kuniyasu H, Chihara Y, Kondo H, Ohmori H, Ukai R. Amphoterin induction in prostatic stromal cells by androgen deprivation is associated with metastatic prostate cancer. Oncol Rep. 2003;10(6): $1863-1868$.

12. Chuangui C, Peng T, Zhentao Y. The expression of high mobility group box 1 is associated with lymph node metastasis and poor prognosis in esophageal squamous cell carcinoma. Pathol Oncol Res. 2012;18(4): 1021-1027.

13. Tarbé N, Evtimova V, Burtscher H, Jarsch M, Alves F, Weidle UH. Transcriptional profiling of cell lines derived from an orthotopic pancreatic tumor model reveals metastasis-associated genes. Anticancer Res. 2001;21(5):3221-3228.

14. Zhang L, Han J, Wu H, et al. The association of HMGB1 expression with clinicopathological significance and prognosis in hepatocellular carcinoma: a meta-analysis and literature review. PLoS One. 2014; 9(10): 110626.

15. Liu PL, Tsai JR, Hwang JJ, et al. High-mobility group box 1-mediated matrix metalloproteinase- 9 expression in non-small cell lung cancer contributes to tumor cell invasiveness. Am J Respir Cell Mol Biol. 2010;43(5):530-538.

16. Kuniyasu H, Chihara Y, Takahashi T. Co-expression of receptor for advanced glycation end products and the ligand amphoterin associates closely with metastasis of colorectal cancer. Oncol Rep. 2003; 10(2):445-448.

17. Kuniyasu H, Sasaki T, Sasahira T, Ohmori H, Takahashi T. Depletion of tumor-infiltrating macrophages is associated with amphoterin expression in colon cancer. Pathobiology. 2004;71(13):129-136.

18. Li Y. The Study of HMGBI's Effect on Lymphangiogenesis and the Mechanism in Colon Cancer [graduation thesis]. The Third Military Medical University. Available from: http://d.wanfangdata.com.cn/ Thesis_Y1179661.aspx. Accessed December 1, 2006.

19. Yao X, Zhao G, Yang H, Hong X, Bie L, Liu G. Overexpression of highmobility group box 1 correlates with tumor progression and poor prognosis in human colorectal carcinoma. J Cancer Res Clin Oncol. 2010; 136(5):677-684.

20. Peng RQ, Li Chunyan, Ding Ya, et al. Expression and clinical significance of high mobility group box 1 in stage IIIB colon cancer. Med $J$ Chin PLA. 2011;36(3):281-286. 
21. Shi Z, Ma H, Yang Z, Qiu W. [Correlation of HMGB1, VEGF, MMP-7 and their relationship with invasion and metastasis of colorectal cancer]. HaiNan Med J. 2012;23:90-91.

22. Sun Xiaochun, Xie Yan, Zhu Wei, Tang Guojian. Clinical significance of HMGB1 and VEGF expression in colorectal cancer tissue. Chin J Clin Lab Sci. 2012;30:927-928.

23. Liu DB. Prognostic Research of Transgelin, MMP-7 and HMGB1 Protein Expression in Rectal Cancer [graduation thesis]. An Hui Medical University. Available from: http://d.wanfangdata.com.cn/ Thesis_D387326.aspx. Accessed May 1, 2013.

24. Zhu L, Li X, Chen Y, Fang J, Ge Z. High-mobility group Box 1: A novel inducer of the epithelial-mesenchymal transition in colorectal carcinoma. Cancer Lett. 2015;357(2):527-534.

25. Ueda M, Takahashi Y, Shinden Y, et al. Prognostic significance of high mobility group box 1 (HMGB1) expression in patients with colorectal cancer. Anticancer Res. 2014;34(10):5357-5362.

26. Süren D, Yıldırım M, Demirpençe Ö, et al. The role of high mobility group box 1 (HMGB1) in colorectal cancer. Med Sci Monit. 2014;20:530-537.

27. Hongo K, Kazama S, Tsuno NH, et al. Immunohistochemical detection of high-mobility group box 1 correlates with resistance of preoperative chemoradiotherapy for lower rectal cancer: a retrospective study. World J Surg Oncol. 2015;13(1):7.

28. Kusume A, Sasahira T, Luo Y, et al. Suppression of dendritic cells by HMGB1 is associated with lymph node metastasis of human colon cancer. Pathobiology. 2009;76(4):155-162.

29. Völp K, Brezniceanu ML, Bösser S, et al. Increased expression of high mobility group box 1 (HMGB1) is associated with an elevated level of the antiapoptotic c-IAP2 protein in human colon carcinomas. Gut. 2006;55(2):234-242.

30. Lee H, Song M, Shin N, et al. Diagnostic significance of serum HMGB1 in colorectal carcinomas. PLoS One. 2012;7(4):e34318.

31. Kijanka G, Hector S, Kay EW, et al. Human IgG antibody profiles differentiate between symptomatic patients with and without colorectal cancer. Gut. 2010;59(1):69-78.

32. Peng RQ, Wu XJ, Ding Y, et al. Co-expression of nuclear and cytoplasmic HMGB1 is inversely associated with infiltration of CD45RO+ $\mathrm{T}$ cells and prognosis in patients with stage IIIB colon cancer. BMC Cancer. 2010;10:496.

33. Li Y, Jiang Y, Shi Y, Shi AX, Peng YL, Liang HJ. Correlation between high mobility group protein1, VEGF-C/D expressions and lymph node metastasis in colon cancer. Acta Acad Med Mil Tertiae. 2006;28:1237-1239.

34. Li Y, Jiang Y, Zhuo WL, Peng YL, Liang HJ. Expression of HMGB1 in colon cancer and its effect on VEGF-C. Chin Clin Oncol. 2007; 12:417-420.

35. Li Y, He JM, Pan F, Li JJ, Liang HJ. The expressions and correlations of HMGBl and VEGF-D in colon cancer. Chin Clin Oncol. 2009; 14:694-697.

36. Dukes CE. The classification of cancer of the rectum.J Pathol Bacteriol. 1932;35(3):323.

37. Compton CC, Greene FL. The staging of colorectal cancer: 2004 and beyond. CA Cancer J Clin. 2004;54(6):295-308.

38. Edge SB, Compton CC. The American Joint Committee on Cancer: the 7th edition of the AJCC cancer staging manual and the future of TNM. Ann Surg Oncol. 2010;17(6):1471-1474.

39. Lotze MT, Tracey KJ. High-mobility group box 1 protein (HMGB1): nuclear weapon in the immune arsenal. Nat Rev Immunol. 2005;5(4): 331-342.

40. Muller S, Scaffidi P, Degryse B, et al. New EMBO members' review: the double life of HMGB1 chromatin protein: architectural factor and extracellular signal. Embo J. 2001;20(16):4337-4340.

41. Dong Xda E, Ito N, Lotze MT, et al. High mobility group box I (HMGB1) release from tumor cells after treatment: implications for development of targeted chemoimmunotherapy. $J$ Immunother. 2007;30(6):596-606.
42. Liu Y, Xie C, Zhang X, et al. Elevated expression of HMGB1 in squamous-cell carcinoma of the head and neck and its clinical significance. Eur J Cancer. 2010;46(16):3007-3015.

43. Liu F, Zhang Y, Peng Z, Gao H, Xu L, Chen M. High expression of high mobility group box $1(\mathrm{hmgb} 1)$ predicts poor prognosis for hepatocellular carcinoma after curative hepatectomy. J Transl Med. 2012;10:135.

44. Kim HJ, Yu MH, Kim H, Byun J, Lee C. Noninvasive molecular biomarkers for the detection of colorectal cancer. BMB Rep. 2008; 41(10):685-692.

45. Soussi T. p53 Antibodies in the sera of patients with various types of cancer: a review. Cancer Res. 2000;60(7):1777-1788.

46. Hanahan D, Weinberg RA. The hallmarks of cancer. Cell. 2000; 100(1):57-70

47. Roncucci L, Fante R, Losi L, et al. Survival for colon and rectal cancer in a population-based cancer registry. Eur J Cancer. 1996; $32 \mathrm{~A}(2): 295-302$.

48. Ohmori H, Luo Y, Kuniyasu H. Non-histone nuclear factor HMGB1 as a therapeutic target in colorectal cancer. Expert Opin Ther Targets. 2011;15(2):183-193.

49. Abe R, Shimizu T, Sugawara H, et al. Regulation of human melanoma growth and metastasis by AGE-AGE receptor interactions. $J$ Invest Dermatol. 2004;122(2):461-467.

50. Kuniyasu H, Chihara Y, Kondo H. Differential effects between amphoterin and advanced glycation end products on colon cancer cells. Int $J$ Cancer. 2003;104(6):722-727.

51. Taguchi A, Blood DC, del Toro G, et al. Blockade of RAGE-amphoterin signalling suppresses tumour growth and metastases. Nature. 2000; 405(6784):354-360.

52. Kostova N, Zlateva S, Ugrinova I, Pasheva E. The expression of HMGB1 protein and its receptor RAGE in human malignant tumors. Mol Cell Biochem. 2010;337(1-2):251-258.

53. Tesniere A, Apetoh L, Ghiringhelli F, et al. Immunogenic cancer cell death: a key-lock paradigm. Curr Opin Immunol. 2008;20(5): 504-511.

54. Gao Q, Ma LL, Gao X, Yan W, Williams P, Yin DP. TLR4 mediates early graft failure after intraportal islet transplantation. Am J Transplant. 2010;10(7):1588-1596.

55. Yang H, Hreggvidsdottir HS, Palmblad K, et al. A critical cysteine is required for HMGB1 binding to Toll-like receptor 4 and activation of macrophage cytokine release. Proc Natl Acad Sci U S A. 2010; 107(26):11942-11947.

56. Czura CJ, Wang H, Tracey KJ. Dual roles for HMGB1: DNA binding and cytokine. J Endotoxin Res. 2001;7(4):315-321.

57. Wang H, Bloom O, Zhang M, et al. HMG-1 as a late mediator of endotoxin lethality in mice. Science. 1999;285(5425):248-251.

58. Kuniyasu H, Yano S, Sasaki T, Sasahira T, Sone S, Ohmori H. Colon cancer cell-derived high mobility group 1 /amphoterin induces growth inhibition and apoptosis in macrophages. Am J Pathol. 2005; 166(3):751-760.

59. Chiba S, Baghdadi M, Akiba H, et al. Tumor-infiltrating DCs suppress nucleic acid-mediated innate immune responses through interactions between the receptor TIM-3 and the alarmin HMGB1. Nat Immunol. 2012;13(9):832-842.

60. Gnanasekar M, Thirugnanam S, Ramaswamy K. Short hairpin RNA (shRNA) constructs targeting high mobility group box-1 (HMGB1) expression leads to inhibition of prostate cancer cell survival and apoptosis. Int J Oncol. 2009;34(2):425-431.

61. Xu J, Futakuchi M, Iigo M, et al. Involvement of macrophage inflammatory protein 1alpha (MIP1alpha) in promotion of rat lung and mammary carcinogenic activity of nanoscale titanium dioxide particles administered by intra-pulmonary spraying. Carcinogenesis. 2010;31(5): 927-935.

62. Fujii K, Luo Y, Sasahira T, Denda A, Ohmori H, Kuniyasu H. Co-treatment with deoxycholic acid and azoxymethane accelerates secretion of HMGB1 in IEC6 intestinal epithelial cells. Cell Prolif. 2009;42(5):701-709. 
OncoTargets and Therapy

\section{Publish your work in this journal}

OncoTargets and Therapy is an international, peer-reviewed, open access journal focusing on the pathological basis of all cancers, potential targets for therapy and treatment protocols employed to improve the management of cancer patients. The journal also focuses on the impact of management programs and new therapeutic agents and protocols on

patient perspectives such as quality of life, adherence and satisfaction. The manuscript management system is completely online and includes a very quick and fair peer-review system, which is all easy to use. Visit http://www.dovepress.com/testimonials.php to read real quotes from published authors.

Submit your manuscript here: http://www.dovepress.com/oncotargets-and-therapy-journal 